INTERNATIONAL DESIGN CONFERENCE - DESIGN 2018

https://doi.org/10.21278/idc.2018.0252

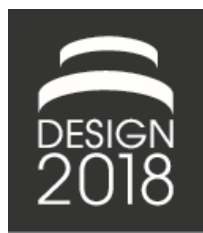

\title{
EVALUATION OF TAF AGILE FRAMEWORK BASED ON THE DEVELOPMENT OF AN INNOVATIVE EMERGENCY WEARABLE FOR SENIORS
}

\author{
L. Spreiter, A. I. Böhmer and U. Lindemann
}

\begin{abstract}
Due to shortened technology lifecycles and changing customer needs, companies are forced to get their products to the market quicker. To overcome these challenges, agile product development methods have been developed. After being widely prevailed in software development, agile methods find their way into hardware development. The TAF Agile Framework provides a procedural model specifically for developing mechatronic products. In this paper TAF is used for the development of an innovative emergency wearable for seniors and is evaluated using an adaption of the 4-Dimensional Analytical Tool.
\end{abstract}

Keywords: agile, mechatronic, prototyping, innovation, evaluation

\section{Introduction}

Today's product development is shaped by uncertainty, shortened development cycles, and increasing product complexity (Lindemann et al., 2009). This was caused by various trends in economy and technology. For example, globalization increases competition for companies all around the world and drives them to develop more variants of their products to fulfill the needs of customers from different countries. Furthermore, customers' needs have changed. Nowadays, people do not want to buy a standard mass-produced products, instead they want products individually tailored to their needs (Kajtaz et al., 2015). To overcome these challenges, agile product development methods like Scrum were developed and successfully applied in software development (Komus et al., 2014). These methods are marked by the use of iterative development cycles and the incorporation of customers throughout the entire process. Prototypes are built incrementally and presented to the customer for feedback to gain knowledge about the product and to optimize it in the next cycle. The TAF Agile Framework combines agile and traditional methods for the development of innovative mechatronic products. It thereby enables fast and customer centric product development, while reducing the complexity of mechatronic product development and maintaining high quality. This framework has been tested during a two-week university course; however, a thorough evaluation is needed to assess its efficacy and make a comparison with other frameworks possible.

\section{Agile product development in hardware}

After their successful application to software development, agile methods are now entering the development of hardware products. In 2016, $34 \%$ of the participants of a study on the success and use of agile methods indicated that they use agile methods for non-IT activities (Komus and Kuberg, 2017). Consequently, first frameworks applying agile methods to hardware development have been presented. 
One example is the "Customer Centric - New Product Development" (CC-NPD) of Romero and Molina, which is focused on the needs and expectations of the intended users. It is comprised of three different phases: divergence, structuring and convergence (Romero and Molina, 2015). In the divergence phase, new ideas are generated by examining customer problems from different perspectives using methods like retro- and prospective and trend analysis. Subsequently, the ideas are structured and rated. This process is supported by the "Jobs-To-Be-Done" framework (Christensen et al., 2016), analyzing the customer expectations, and the "Outcome Expectations" opportunity grid, comparing the expectations of customers and company. Further methods in this phase are ethnographic tools, e.g., market studies, or the "Value Proposition Canvas" (Osterwalder et al., 2014). The objective of the convergence phase is merging the ideas and expectations into a real product. Using methods and artefacts like the "Analytical Hierarchical Process" or the "House of Quality", it is possible to transform customer needs into technical specifications and parameters (Romero and Molina, 2015). Using simple prototypes, different alternatives can be tested to generate knowledge and improve the solution. The ideal overall solution can then be found using TRIZ (Altshuller, 1973), defined as the solution that comprises the most useful functions with the least amount of undesirable side effects and costs. This solution then can be implemented in a functional prototype, which models the products aesthetic, material and functionalities.

Another framework for agile hardware development is the Three Canvas Model by Link and Lewrick (2014). This model expands the business model canvas from Osterwalder et al. (2014) with two additional canvases - product vision and customer - in order to apply it to the three innovation domains viability, feasibility and desirability. It combines the core values of a product with information about the users and stakeholders and gives technical specifications like functions, interfaces and constraints. The three canvases are initially filled with assumptions and then iteratively tested until a final product and business model is derived.

Both frameworks already have been applied successfully in corporate and research projects. CC-NPD was created based on the experience of 10 consulting projects and 250 student projects. $75 \%$ of the prototypes crafted by the students were transformed into real products (Romero and Molina, 2015). The Three Canvas Model was evaluated in different workshops at Swiss companies over a period of one year, showing advantages in creating a joint understanding, focusing on key aspects and keeping the development process agile (Link and Lewrick, 2014). It has been shown, that the development of hardware products also benefits from agile methods. But current frameworks do not provide the methods necessary to cope with the increased complexity of mechatronic products, which combine the three disciplines of mechanics, informatics and electronics (Hostettler et al., 2017).

\section{TAF Agile Framework}

The TAF Agile Framework provides a methods framework for the agile development of mechatronic products. The framework segments the development process into three independent Plan-Do-CheckAct cycles (PDCA) (Deming, 1986) for the three domains desirability, feasibility and viability. In every cycle, a product increment is created, resulting in a final prototype, representing the maximum overlap of all dimensions. The development starts with a product vision and aims to reduce the uncertainty with regard to all aspects of the product. Therefore, the framework acts as a guideline by providing artefacts. Objective of the desirability cycle is the validity evaluation of user stories. User stories are formulated, and the underlying assumptions are transformed into hypotheses. For every hypothesis, a success criterion and quantitative test is defined for verification using a prototype. The feasibility cycle evaluates a product's technical feasibility. A functional model is derived based on technical user stories and a morphological box created to explore the solution space. Necessary specifications are documented in a requirements list and rated based on their importance regarding the team's knowledge and the product. The most critical requirements are analyzed by building a prototype. The viability cycle aims to determine whether a functioning business model can be built based on the current knowledge about the product. Fundamental assumptions about the business model are defined in a lean canvas (Blank, 2013). A market research aims to determine the potential market size. This can be compared with a ballpark cost estimation determining the viability of a business model. The three cycles are carried out in parallel and synchronized in the act-phase of the PDCA cycle, where the uncertainty in every domain is analyzed and resources allocated accordingly. If one cycle ends before the others, an asynchronous act meeting 
is held to decide whether the information of the running cycle is still relevant to the product. If not, the cycle is terminated. TAF was evaluated during the fifth iteration of Think.Make.Start, a lab course at Technical University of Munich. Using the framework, all teams were able to present working prototypes, which also showed a higher complexity and more implemented critical functions than the prototypes in previous iterations, where TAF was not used.

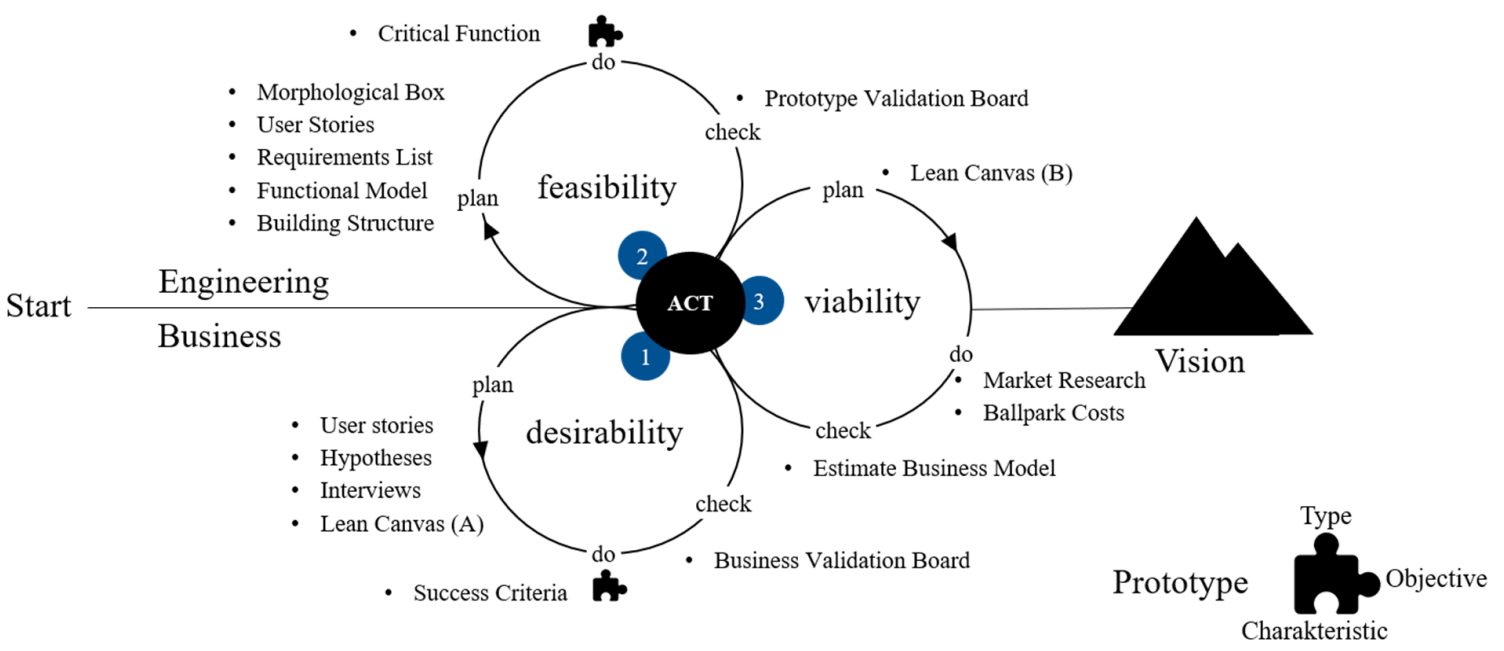

Figure 1. TAF Agile Framework

\section{Development of an innovative emergency wearable for seniors}

During the second edition of Think.Make.Start (TMS) in 2015, the team "Solemove" developed a falling recognition and emergency shoe for seniors (Böhmer et al., 2016). Its purpose was to provide senior citizen afraid of falling with a constant feeling of safety, as well as notify their relatives in case of an emergency. A fall detection algorithm automatically triggered an alarm and sent a notification, as soon as a person wearing the wearable fell. For seniors suffering from dementia, the shoe was also equipped with a positioning system to locate a missing person. Since senior citizen often deeply care about their appearance and the impression they make, they often do not want to wear a device showing their need for assistance. Therefore, the objective was to invisibly integrate the solution into an everyday object that is worn daily. A minimum viable product was built, consisting of a shoe, where the original sole was replaced by a 3Dprinted housing for the electronic components. Falling was recognized using data from an accelerometer. An alarm was issued by the detection algorithm implemented on an Arduino-Microcontroller, if a predefined acceleration threshold was exceeded. A Bluetooth module established a connection to a smartphone, which in turn sent the alarm in form of a text message to predefined phone numbers. Furthermore, a GPS module was integrated to remotely locate the wearer of the shoe (see Figure 2).

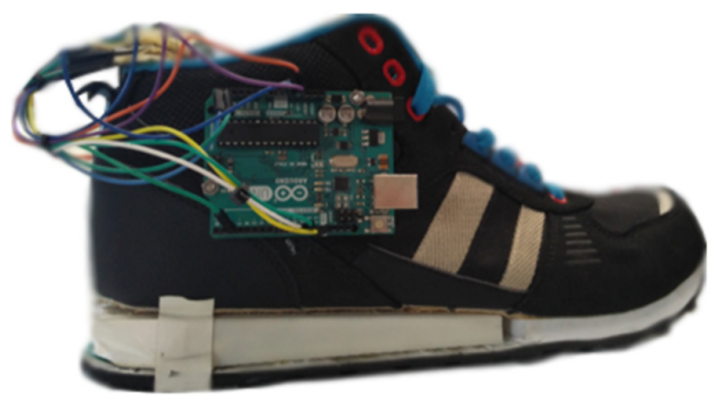

Figure 2. Think.Make.Start prototype of "Solemove"

Starting with this prototype the development of the emergency wearable was performed using the TAF Agile Framework. The cycles for desirability, feasibility, and viability were examined in parallel and 
the design of the final product was derived after four iterations of the desirability cycle and three iterations of the feasibility and viability cycles. The development team consisted of an interdisciplinary team of three students from mechanical engineering, informatics and business studies.

\subsection{Desirability}

The initial vision for the product was the integration of an emergency device into an interchangeable shoe inlay sole for use in different shoes. For this scenario four user stories were defined. First, seniors want to have a device to call for help in emergency situations. The device should also be able to call for help automatically, if the wearer is not able to trigger an alarm manually. Furthermore, the device should be invisible to hide the need for assistance from others. Caretakers wish for a device that can determine the position of the wearer, so that they can provide immediate help in emergency situations. To determine the validity of these user stories, the TMS prototype was shown to senior citizen and their caretakers. Using a standard leather inlay sole, the intended users' ability to change a sole in short time was tested and to understand whether this solution is desirable. Interviews confirmed that caretakers want a device to access the position of their patients and that seniors want the device to automatically detect emergencies. However, the integration of the device in an inlay sole turned out to be not desirable. Senior citizen were not able to insert the sole into a shoe in less than 30 seconds; they also remarked that they are wearing a lot of different shoes, requiring many changes in practice. They also reported that they often do not wear shoes at home. Based on these findings an act-meeting was convened and the integration into a shoe discarded.

In the second iteration of the desirability cycle, a new wearable for integration of the emergency device had to be found. Brainstorming led to six different ideas: wristband, watch, belt, plaster, foot strap, and necklace.

To determine the desirability of a solution, small wood prototypes were built (see Figure 3) and presented to ten seniors in an assisted living facility, where seniors live in their own homes, but get support on their daily life from professional caretakers. The small focus group was chosen because of its easy accessibility and its spontaneous and unbiased feedback. 7 women and 3 men took part in the product presentation, achieving a typical distribution of seniors. Furthermore, three participants were already wearing an emergency call button and could compare the presented solution with their own experiences.

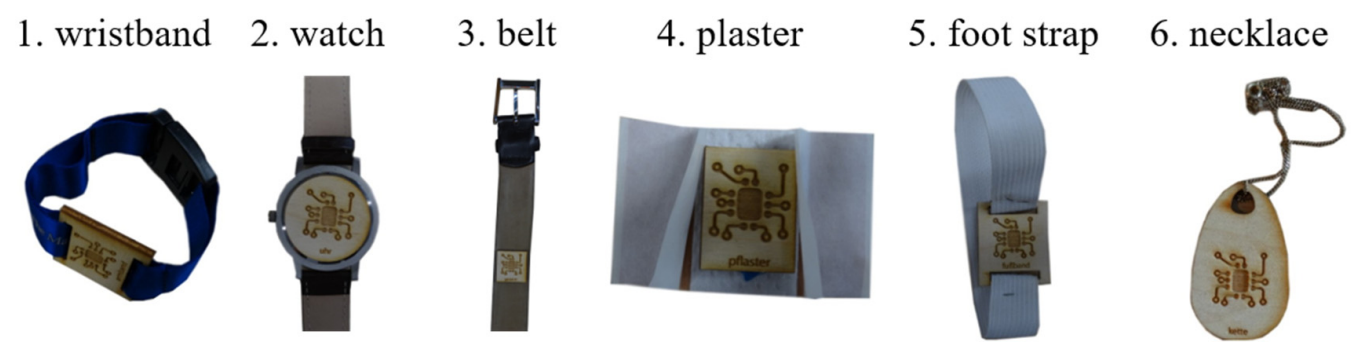

Figure 3. Desirability prototypes of the second iteration

The requirement for a wearableto be accepted was that eight or more of the ten seniors found it attractive. This requirement was not met by any of the specified solutions. Seniors favored different solutions; the wristband was leading, reaching an acceptance rate of seven seniors, followed by the watch (five seniors) and the necklace (four seniors). The plaster and the foot strap were widely rejected, because of concerns regarding allergies against plaster adhesives and the visibility of the foot strap, while wearing a skirt. It became clear, that a single wearable was not desirable for most senior citizen.

In the following act-phase, the decision was made to focus on a modular approach in the third iteration allowing the users to change between different wearables. The first approach to implement this was a two-component housing, consisting of an upper part, carrying all the electronics, and an exchangeable lower part, which could be built in different configurations, like a wristband, belt-clip or necklace. The connection between both parts was designed like a screw-cap, assuming seniors could easily handle this coupling, since it is well known from bottles. A 3D-printed prototype for the upper part and three different lower parts, designed as necklace, wristband, and adhesive housing to be glued to any given 
item (see Figure 4) was built. This prototype was intended to determine the desirability of a modular solution and the feasibility of the screwing mechanism, whether seniors can change between two variants in less than a minute. Again, a hypothesis was accepted if eight or more seniors support it. While the modular approach found broad approval, the screw top was not easily operated by the participants because trembling hands and their inability to precisely position the housing-parts. Especially the adhesive solution was hard to disassemble, because it did not have enough space to grab it. However, most participants also needed several attempts to assemble the prototypes of the other solutions. As a result, the modular approach was accepted, while the screwing mechanism was rejected.

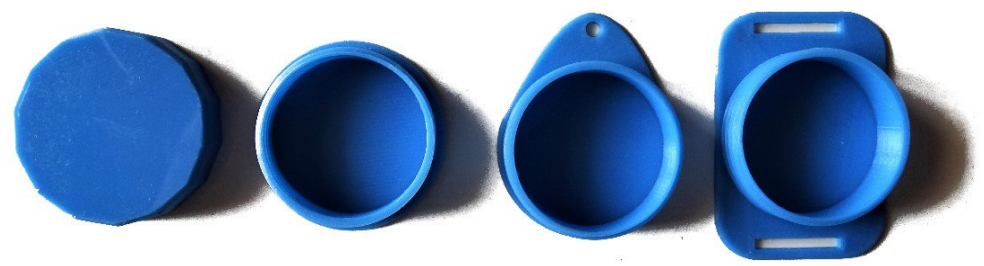

Figure 4. Desirability prototypes of the third iteration

Objective of the fourth desirability cycle was finding an easier and more desirable assembly mechanism. Two other possible mounting mechanisms were identified: clicking or sliding the housings into another. Again, 3D-printed prototypes were built for each type (see Figure 5) and presented to seniors. Since the clicking-mechanism required precise positioning and application of pressure, only two out of the eight senior participants were able to assemble and disassemble it. However, sliding was easier to handle and all of the testing seniors were able to disassemble and assemble the housings in less than a minute.
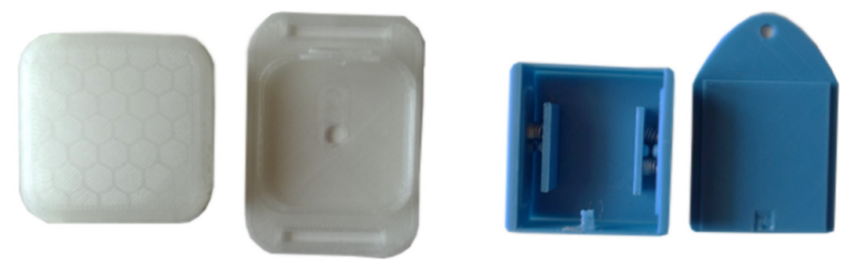

\section{Figure 5. Desirability prototypes of the fourth iteration}

Result of the desirability cycles is the concept of a modular wearable, which is able to automatically detect falls, send alarms and positioning information. The device consists of a two-component housing, which can be a wristband, belt clip or necklace. Therefore, it allows every senior to wear it the way he likes it best, offering more comfort and discreetness to the wearer.

\subsection{Feasibility}

The feasibility cycle was carried out in parallel to the desirability considerations. Technical user stories were specified, defining seniors as the primary users, who want a comfortable device to call for help in emergency situations and to automatically detect emergencies. Furthermore, caretakers want to have a device to get location information of their patients, in order to locate them quickly in dangerous situations. Based on these stories, a requirements specification was created, containing demands for functionalities and comfort features. Every requirement was rated from zero (not critical) to ten (very critical) based on the initial team knowledge about it and their relevance for the product. The specifications on a minimum space, alarm system, reliable fall detection, battery runtime and comfort of exchanging the inlay sole between different shoes were most critical. Prototypes to test these specifications were planned, but not carried out, because the first iteration was aborted, after the desirability cycle identified the inlay sole as a non-desirable solution.

In the second iteration of the feasibility cycle, no specific object for integration of the device was defined. Therefore, some requirements, like the dimensions of the device, could not be specified. Also, the fall detection could not be tested, because the algorithm depends on the position of the device on the wearer body. The alarm system was tested using a prototypical design made of an Arduino board, a GSM and GPS-module and a button (see Figure 6). 


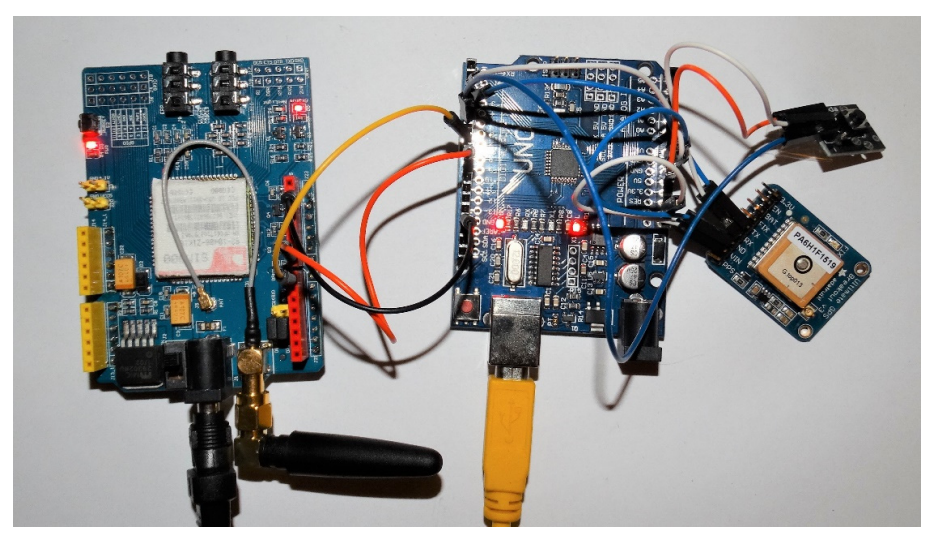

Figure 6. GSM-module, Arduino, GPS module and button

For the battery runtime, a rough calculation was conducted, summing up the power consumption of the electrical components, like microcontrollers, GSM and GPS modules, and Bluetooth. For a minimum runtime of 14 hours, assuming the device is charged overnight, a capacity of $314 \mathrm{mAh}$ was calculated. The ideal battery capacity for 24-hour runtime amounts to $538 \mathrm{mAh}$. After the concept of a modular approach with different possible wearing positions was defined, it was necessary to determine which body positions are feasible for falling recognition. Therefore, experiments were performed for the following wearing position: wrist, neck, hip and foot. The fall detection algorithm was able to detect all falls at the position of the necklace, wristband and belt, but missed two out of 14 falls at the foot-strap position (see Figure 7). Based on an acceptance criterion of more than $90 \%$ sensitivity, it was decided, to not further develop the foot strap module.
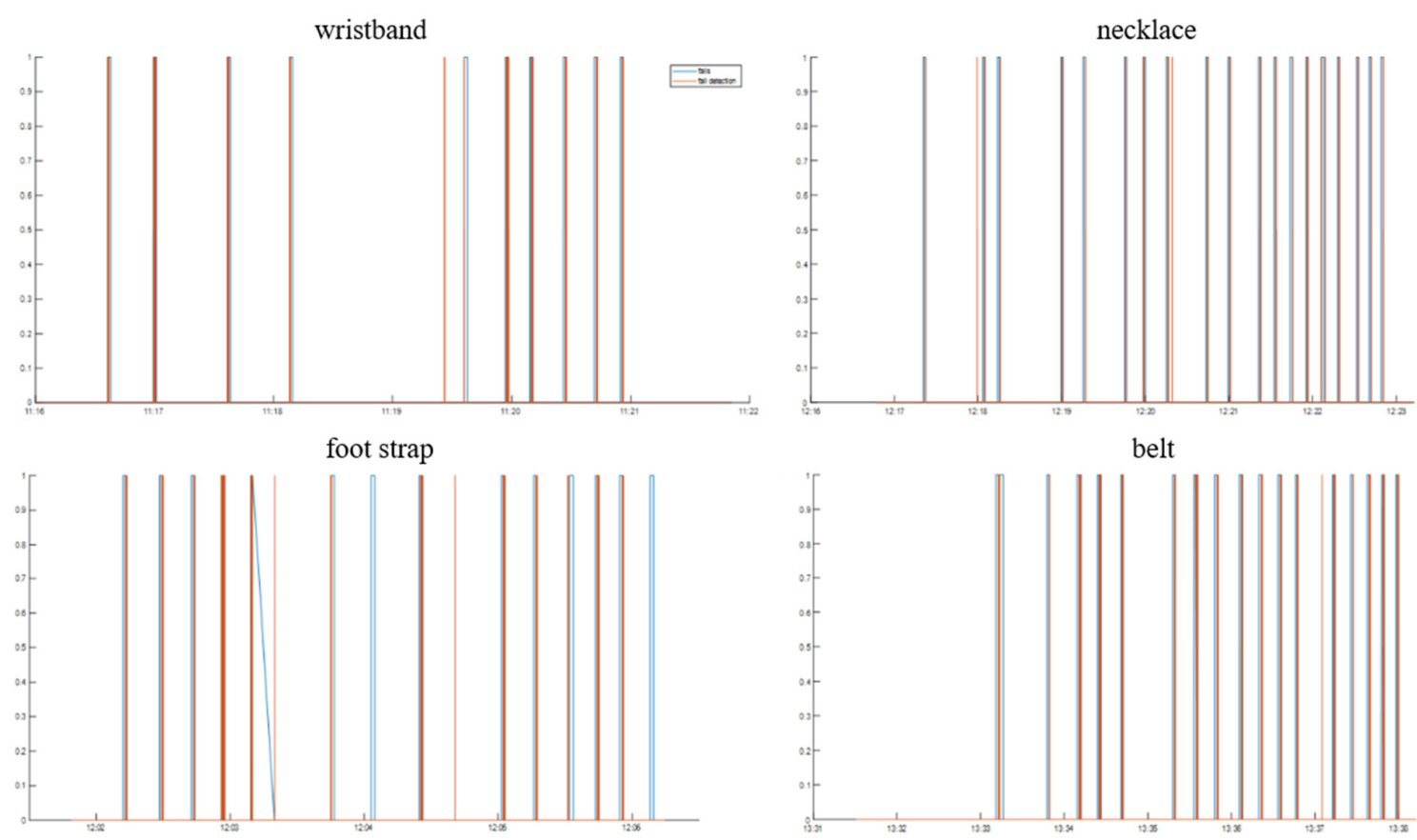

Figure 7. Results of the falling detection

To define the maximum dimensions, a benchmark was carried out comparing different emergency devices for seniors. Based on the result the maximum space was fixed to $50 \mathrm{~mm}$ x $50 \mathrm{~mm}$ x $20 \mathrm{~mm}$. To determine, whether the proposed solution can be built in these dimensions, a CAD model was created, combining models of possible components with a self-constructed housing (see Figure 8). With $34 \mathrm{~mm}$ $\mathrm{x} 40 \mathrm{~mm} \times 14 \mathrm{~mm}$, the designed model is still meeting these requirements. 
During desirability testing with seniors, another feasibility requirement emerged, regarding the required force to actuate the mounting mechanisms for changing the modules. Because many seniors are suffering from a decline in physical abilities, the mechanism must be easy to handle. A maximum pressure of 10 $\mathrm{N}$ or one eighth of a seniors maximal finger strength (Rickert, 2010) to disassemble the housing was postulated. A magnetic lock was designed to match these requirements.

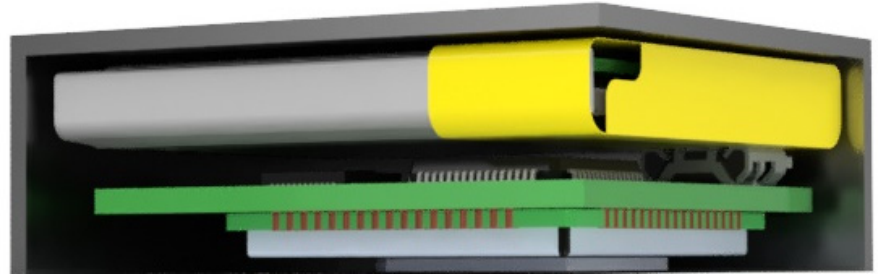

Figure 8. CAD-model of the device

\subsection{Viability}

Objective of the viability cycle is finding a viable business model for the product. In the first iteration, the intended user group was defined. The intended users consist of different groups: home users, including senior citizens living at home and their relatives, and professional users, like nursing homes or clinics. Channels to reach these customers were nursing homes, clinics, emergency service providers, health care supply stores and print media. Direct sale of the shoe inlay sole or a monthly fee for renting it were defined as revenue streams. Costs split in hard- and software development, production, sales and monthly costs for operating an emergency call center. The serviceable obtainable market comprises around 250.000 people. A ballpark cost estimation resulted in approximately costs of 8 million euro a year. Assuming a purchase price of 100 euro and a monthly fee of 40 euro, the revenue per year adds up to 145 million euro, indicating a viable business. An increasing number of seniors worldwide (Lunenfeld, 2008) adds further backing to the viability of the product. In the second viability iteration, a benchmark with competitor products was derived. While the competitor's retail prices of more than 500 euros were much higher, than the target price of the device proposed here, the monthly fees started at a comparatively low fee of 15 euros. To be more competitive and further distinguish from the competition, the development of a new pricing model was necessary. Based on the modular approach of the wearable itself, the idea emerged to also offer a modular pricing model. Additional functionalities, e.g. the automatic fall detection or a connection to an emergency center, can be added individually to the basic version comprised of the rent for the device and the connection to predefined numbers of relative. Professional users are charged more and can book more features, like an analysis of the activity data of their patients. Table 1 shows an example pricing model.

Table 1. Example pricing model

\begin{tabular}{lll}
\hline \hline Name & B2C & B2B \\
\hline \hline Rent device incl. private number & $12 €$ & $15 €$ \\
\hline Connection emergency centre & $10 €$ & $10 €$ \\
\hline Positioning & $3 €$ & $3 €$ \\
\hline Automatic fall detection & $8 €$ & $10 €$ \\
\hline Geotracking & $3 €$ & $3 €$ \\
\hline Analysis of activity data & $\mathrm{X}$ & $4 €$ \\
\hline Maximal total costs & $36 €$ & $45 €$ \\
\hline \hline
\end{tabular}

\subsection{Final product}

Seniors often fall and need help to stand up again, as well as with dementia patients getting lost. The developed product aims to solve this problem. It integrates an emergency call and localization system into a wearable device. Unique value propositions are the automatic fall detection based on machine 
learning algorithms and the modular approach, so patients can choose and change the position of the device on the body. Customers are private users, especially senior citizen and their relatives, as well as professional users, like nursing centers or clinics. The device can be rented for a basic price and individual features can be booked separately. Figure 9 shows the final prototype of the product, consisting of the electronic module and three interchangeable 3D-printed housing modules for wear on a belt, as a necklace, and as a wristband.

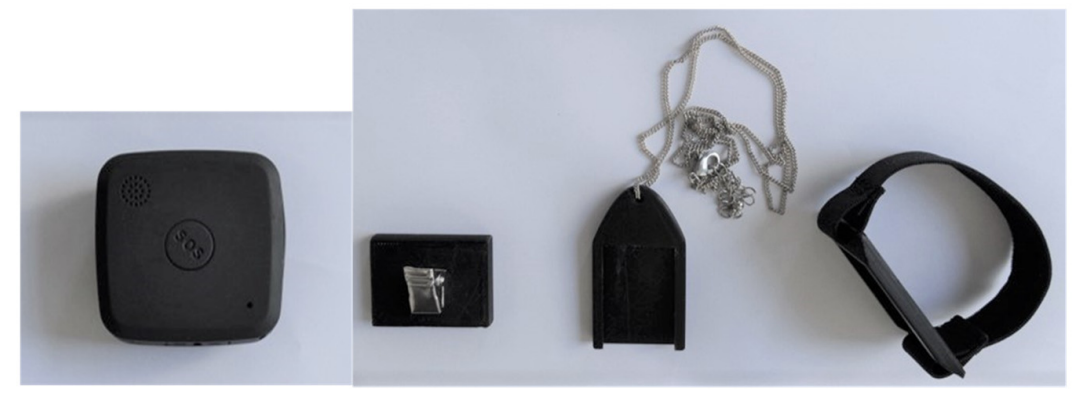

Figure 9. Final product with modules for belt clip, necklace and wristband

\section{Evaluation methodology}

The four-dimensional analytical tool (4-DAT) was used to evaluate TAF. Because 4-DAT is an evaluation tool for software development methods, it was modified to fit frameworks for the development of physical products. 4-DAT structures the evaluation in four dimensions: "method scope characterization, agility characterization, agile values (agile manifesto) characterization and software process characterization" (Qumer and Henderson-Sellers, 2007). The first dimension evaluates the framework on its basic parameters. The criteria "Code Style" and "Abstraction Mechanism" are software-specific and were replaced with the criteria "Product Types", describing the types of products the method supports, e.g. medical products. Dimension two evaluates the framework on five different agility features: flexibility (FY), speed (SD), leanness (LS), learning (LG) and responsiveness (RS). For every phase and practice of the method, it is tested whether it supports one of those features (corresponding to "1") or not ("0"), allowing a quantitative measurement of a frameworks agility. The third dimension evaluates the method based on six agile values. Four are provided by the agile manifesto, the fifth examines which practices help to keep the process agile and the sixth which keep it cost efficient. The fourth dimension, usually characterizing software processes, was modified for physical product development. The criteria "Development Process", evaluating which practices cover the lifecycle and testing, and "Project Management Process", dealing with the overall project management, were kept without changes. "Software Configuration Control Process" and "Process Management Process" were replaced with the criteria "Documentation", covering the practices that deal with the documentation of the development process, and "Complexity", evaluating the practices, that handle the complexity of mechatronic products.

\section{Evaluation of TAF Agile Framework}

After the development, a reflection workshop was carried out together with the development team and a start-up, developing emergency and healthcare wearables for seniors and chronic patients. The development of the emergency wearable was presented and TAF evaluated using the adapted 4-DAT. Team sizes varied between two people to five people, but small teams up to ten people can easily be covered. By creating sub teams for every cycle of feasibility, desirability, and viability even bigger teams become possible. TAF works with three independent development cycles, creating and evaluating prototypes iteratively using rapid-prototyping technologies, like 3D-printing or microcontroller platforms, like Arduino. The team members need to work closely together and interact with customers; therefore, a co-located work environment is necessary. In every individual cycle, the team member work collaboratively towards a discipline specific objective and the whole team cooperates on the overall objective. TAF was especially designed to fit the requirements of developing mechatronic products (see Table 2). 
Table 2. Scope evaluation of TAF

\begin{tabular}{ll}
\hline \hline Criteria & TAF \\
\hline Project Size & Small to medium innovation projects \\
\hline Team Size & Small teams with less than 10 people \\
\hline Development Style & Iterative, three independent cycles \\
\hline Technology Environment & Rapid-prototyping, paper-prototyping, sketches, models, survey, microcontroller platforms \\
\hline Physical Environment & Co-located collaboration \\
\hline Business culture & Collaborative and cooperative \\
\hline Product Types & Hardware products, especially mechatronic products \\
\hline
\end{tabular}

In the quantitative agility evaluation, the four phases of TAF show a lack of flexibility. TAF provides a concrete guideline on what to do and which artefacts to create in every phase. Every cycle is carried out separated from the others making decisions only possible in the act phase, where all cycles are synchronized. However, the asynchronous act-meeting allows to react on changes in one cycle, even if the other cycles have not reached the act-phase. Increasing the responsiveness of the framework and making the asynchronous synchronisation the most agile practice. In the development of the wearable, this led to cancellation of the feasibility and viability cycles in the first iteration, after the shoe inlay sole turned out to be undesirable. Gained knowledge from one iteration is transferred to the planning phase of the next cycle enabling to build up on previous experiences. For example, the gained knowledge from the development of the locking system was used to incrementally optimize it in every iteration in the desirability and feasibility cycle. Integration of traditional methods, like a requirement list, reduce the flexibility and speed of the development on the one hand, but keep track of valuable learnings and strengthen the leanness by increasing the quality of the development process and the product on the other hand. The degree of agility of TAF can now be calculated using the number of elements $m_{D A}$, rated with "1", divided by the total number of elements:

$$
D A_{\text {total }}=\frac{1}{m_{\text {total }}} \times \sum m_{D A, \text { total }}=\frac{36}{50}=0.72
$$

Overall, the degree of agility of the phases was rated 0.75 of 1 . In evaluating the practices, the integration of traditional methods with the lowest value for agility is assessed. While this practice leverages learning and contributes to a leaner development process, it also reduces the flexibility and speed of development. In particular, asynchronous cycle synchronization contributes to increased agility, as does the division of development into the three domains feasibility, desirability and viability. Table 3 shows the evaluation of the phases of TAF in terms of agility and the assessment of TAF practices against the five agility sizes. If a criterion is supported, this is marked with a "1".

Table 3. Quantitative evaluation of agility

\begin{tabular}{l|l|l|l|l|l|l}
\hline \hline \multicolumn{7}{l}{ Agility values } \\
\hline \hline TAF & FY & SD & LS & LG & RS & Sum \\
\hline (1) Phases & & & & & & \\
\hline Plan & 0 & 1 & 1 & 1 & 1 & $\mathbf{4 / 5}$ \\
\hline Do & 0 & 1 & 1 & 1 & 1 & $\mathbf{4 / 5}$ \\
\hline Check & 0 & 0 & 0 & 1 & 1 & $\mathbf{2 / 5}$ \\
\hline Act & 1 & 1 & 1 & 1 & 1 & $\mathbf{5 / 5}$ \\
\hline Degree of agility & $\mathbf{1 / 4}$ & $\mathbf{3 / 4}$ & $\mathbf{3 / 4}$ & $\mathbf{4} / \mathbf{4}$ & $\mathbf{4 / 4}$ & $\mathbf{1 5 / 2 0}$ \\
\hline \hline (2) Practices & & & & & & \\
\hline Separation FDV & 1 & 1 & 0 & 1 & 1 & $\mathbf{4 / 5}$ \\
\hline Act-Meeting & 1 & 1 & 1 & 1 & 0 & $\mathbf{4 / 5}$ \\
\hline Asynchronous Cyclesynchron. & 1 & 1 & 1 & 1 & 1 & $\mathbf{5 / 5}$ \\
\hline Prototyping & 0 & 1 & 0 & 1 & 1 & $\mathbf{3 / 5}$ \\
\hline Provided artefacts & 0 & 1 & 1 & 1 & 0 & $\mathbf{3 / 5}$ \\
\hline Integration of traditional methods & 0 & 0 & 1 & 1 & 0 & $\mathbf{2 / 5}$ \\
\hline Degree of agility & $\mathbf{3 / 6}$ & $\mathbf{5 / 6}$ & $\mathbf{4 / 6}$ & $\mathbf{6 / 6}$ & $\mathbf{3 / 6}$ & $\mathbf{2 1 / 3 0}$ \\
\hline
\end{tabular}


Analyzing the degree of agility based on the Agile Manifesto (Beck et al., 2001), we can see that individuals are focus of the development using TAF. Individual teams are built for the three innovation domains of desirability, feasibility and viability focusing on different domains of expertise and are marked by high communication and collaboration. By building prototypes and presenting them to customers, TAF emphasizes the importance of interactions and idea exchange. Every iteration of TAF features three different PDCA cycles, each working on a prototype to gain knowledge and to collaborate with customers. Especially in the desirability cycle, the interaction with customers is essential, because it focuses on discovering their needs and wishes, e.g. different wearables were presented to the seniors to find out, which one they like best. The act-meeting brings all three dimensions together and determines whether the developed product is still desirable, feasible and viable. If a change occurs in one of these dimensions, possible reactions will be discussed and resources are assigned accordingly. Provided artefacts keep the development cost-efficient by leading the developers through the process and ensuring that no resources are wasted.

Table 4. Degree of agility

\begin{tabular}{ll}
\hline \hline Criteria & TAF \\
\hline \hline Individuals and interactions & Act-Meeting, Separation FDV, Prototyping \\
\hline Working prototypes & Prototyping, PDCA-Cycle \\
\hline Customer Collaboration & Prototyping, PDCA-Cycle, Desirability \\
\hline Responding to change & Act-Meeting, Asynchronous Cycle-Synchronization \\
\hline Agile processes & Separation FDV, Asynchronous Cycle-Synchronization \\
\hline Cost-efficient processes & Provided artefacts \\
\hline \hline
\end{tabular}

Table 5. Process evaluation

\begin{tabular}{ll}
\hline \hline Criteria & TAF \\
\hline \hline Development Process & FDV, Requirement list \\
\hline Project Management & Independent cycles, Act-Meeting, Provided artefacts \\
\hline Documentation & Provided artefacts \\
\hline Complexity & Morphological box, requirements list \\
\hline \hline
\end{tabular}

The last dimension of 4-DAT evaluates the processes within the framework and handling documentation and complexity. TAF deals with the whole life cycle of a product, starting with the analysis of customer requirements in the desirability cycle continuing with the feasibility analysis and the development of a viable business and marketing model. While TAF offers methods to design concepts for these lifecycle phases, it is not used during later product phases, like production. Furthermore, the framework does not offer methods specifically for project management, but rather focuses on collaboration between individuals. Provided artefacts guide through the development process. The act-meeting finally provides an information exchange between the parallel. While TAF proposes an agile development method, it still emphasizes the need of documentation for hardware products. Provided artefacts support focusing on important tasks and recording specifications for later phases. Complexity primarily occurs in the feasibility cycle, because it combines the three dimensions of mechanics, electronics and informatics in a single product. The morphological box helps to assemble the best solution out of a large solution space, including all three dimensions. Using the requirements list, critical features can be identified.

\section{Discussion and outlook}

In this paper, the development of an innovative emergency wearable for seniors using the TAF Agile Framework was presented. Based on a prototype of a fall-detection integrated into a shoe sole, a modular device, was developed, which can be worn on different body positions and offers various functionalities, like emergency calls, automatic fall detection and localisation services. The desirability of the solution was analyzed by iteratively building different prototypes and presenting them to potential users. Furthermore, prototypes were built to determine the feasibility of the solution. The products viability 
was analyzed, and a modular business model was developed allowing users to subscribe to different services individually on a monthly basis. Subsequently, the TAF Agile Framework was evaluated using the 4-DAT evaluation method, adapted to development methods for hardware products. TAF is suitable for small to medium innovation projects, especially for the development of mechatronic products. The asynchronous cycle synchronization adds most to the agility of the framework because it allows for adapting to changes at any point in time.

The development process is accelerated, as the framework focuses on early prototypes in the category of desirability, feasibility, and viability. In accordance with Menold et al. (2016), the prototypes improve the understanding of the development process and highlight the potential that structured prototyping methods could have on end designs. In the development of the wearable for seniors resulted in a novel modular approach for wearables, as well as in a flexible pricing model. The product specifications are arisen gradually over time, when testing the prototypes with the user. The testing resulted in an improved design that addresses the elderly specific needs. The iterative approach allows gradual evolution of the product, with each stage being tested by the user and building on the experience gained from it. This makes it possible to redefine the project process repeatedly and in a user-centred way. The knowledge gained during testing is used for the development of subsequent prototypes, which is the essence of agile approaches (Gnatz, 2005, p. 22).

The framework could be improved by setting a fixed maximum duration for its iterations for better planning and tracking. Furthermore, a kick-off meeting should be introduced to initially frame the scope of the project. Rating the criticality of features in the feasibility analysis poses another difficulty, since this mostly relies on a subjective estimation of the project team. Here objective methods, i.e., a multiple domain matrix, could be introduced to support the estimation. Main limitation for this evaluation is that the development team consists of students. Future work will comprise an advanced project team. Additionally, TAF needs to be applied in bigger teams and projects to evaluate its benefits in an industrial context. Results of the emergency wearable' development has been reflected with an existing start-up, addressing a similar topic. It is found out that the concept developed with TAF addresses more user requirements. However, the start-up stresses the viability of the product and thus focuses on few user requirements to survive in a competitive market.

\section{References}

Altshuller, G. (1973), The Innovation Algorithm, Technical Innovation Center Inc, Worcester, MA.

Beck, K., Beedle, M., van Bennekum, A., Cockburn, W., Fowler, M. et al. (2001), Agile Manifesto. [online] Available at: http://agilemanifesto.org/iso/de/principles.html (accessed 08.06.2017).

Blank, S. (2013), "Why the lean start-up changes everything", Harvard business review, Vol. 91 No. 5, pp. 63-72.

Böhmer, A.I., Richter, C., Hostettler, R., Schneider, P., Plum, I. et al. (2016), "Think.Make.Start. An Agile Framework", Proceedings of the DESIGN 2016 / 14th International Design Conference, Dubrovnik, Croatia, May 16-19, 2016, The Design Society, Glasgow, pp. 917-926.

Christensen, C.M., Hall, T., Dillon, K. and Duncan, D.S. (2016), "Know Your Customers' "Jobs to Be Done"', Harvard Business Review, Vol. 94 No. 9, pp. 54-62.

Deming, W.E. (1986), Out of the crisis, Cambridge University Press, Cambridge, MA.

Hostettler, R., Böhmer, A.I., Lindemann, U. and Knoll, A. (2017), "TAF Agile Framework", Proceedings of ICE/ITMC'17 / the 23th International Conference on Engineering, Technology and Innovation, Madeira, Portugal, June 27-29, 2017, IEEE, pp. 788-796. https://doi.org/10.1109/ICE.2017.8279962

Kajtaz, M., Witherow, B., Usma, C., Brandt, M. and Subic, A. (2015), "An approach for personalised product development”, Procedia Technology, Vol. 20, pp. 191-198. https://doi.org/10.1016/j.protcy.2015.07.031

Komus, A. (2012), Status quo agile - Studie zur Verbreitung und Nutzen agiler Methoden, Hochschule Koblenz, p. 24.

Komus, A. (2017), Abschlussbericht: Status Quo Agile 2016/2017 - Studie über Erfolg und Anwendungsformen von agilen Methoden, Hochschule Koblenz.

Kyhnau, J. and Nielsen, C. (2015), "Value Proposition Design: How to create products and services customers want”, Journal of Business Models, Vol. 3 No. 1, pp. 81-92. https://doi.org/10.5278/ojs.jbm.v3i1.1105

Lindemann, U., Maurer, M. and Braun, T. (2009), Structural complexity management: an approach for the field of product design, Springer, Berlin, Heidelberg. https://doi.org/10.1007/978-3-540-87889-6 
Link, P. and Lewrick, M. (2014), “Agile Methods in a New Area of Innovation Management”, Proceedings of the $13^{\text {th }}$ International Science-to-Business Marketing Conference on Cross Organizational Value Creation, Winterthur, Switzerland, June 2-4, 2014, Fachhochschule Münster, pp. 321-337.

Lunenfeld, B. (2008), “An Aging World - Demographics and challenges”, Gynecological Endocrinology, Vol. 24 No. 1, pp. 1-3. https://doi.org/10.1080/09513590701718364

Menold, J., Simpson, T.W. and Jablokow, K.W. (2016), “The Prototype for X (PFX) Framework: Assessing the Impact of PFX on Desirability, Feasibility, and Viability of End Designs", Proceedings of the ASME 2016 International Design Engineering Technical Conferences and Computers and Information in Engineering Conference, Vol. 7, Charlotte, USA, August 21-24, 2016, ASME, pp. V007T06A040. https://doi.org/10.1115/DETC2016-60225

Qumer, A. and Henderson-Sellers, B. (2007), "Measuring Agility and Adoptability of Agile Methods: A 4dimensional Analytical Tool", Proceedings of the IADIS International Conference Applied Computing 2006, San Sebastian, Spain, February 25-28, 2006, IADIS, pp. 503-507.

Rickert, M. (2010), Funktionelle Normwerte und Einflussfaktoren an Unterarm und Hand gesunder männlicher Erwachsener, PhD thesis, LMU München.

Romero, D. and Molina, A. (2015), "A multidisciplinary framework and toolkit to innovate customer-centric new product development", Proceedings of the ICE/ITMC'15 / the 21st International Conference on Engineering, Technology and Innovation, Belfast, UK, June 22-24, 2015, IEEE, pp. 1-10. https://doi.org/10.1109/ICE.2015.7438638

Annette Isabel Böhmer, Dipl.-Ing.

Technical University of Munich, Laboratory for Product Development and Lightweight Design

Wirtsbreite, 80939 München, Germany

Email: annette.boehmer@tum.de 